Oksana PIETSUKH

\title{
NONVERBAL COMMUNICATION MEANS IN THE UK PARLIAMENTARY DEBATES
}

\begin{abstract}
This article focuses on the proxemics, oculesics and tacesics as nonverbal communication peculiarities in the UK parliamentary debates within the scope of parliamentary discourse studies (discoursology) as a new branch of political discourse studies. It deals with studies of metonymy-based language representations of space used to name the MPs in the UK parliamentary debates. Here, the visual characteristics and behavioral patterns influencing MPs' role and participation in the debates are highlighted. The paper determines cognitive background and extralinguistic factors influencing the usage of naming models and MPs' colour determination in parliamentary debates. Such debates represent the events regardless of the party that gains the majority in the UK parliament in post-Thatcher period. It is concluded that nonverbal communication has become an inseparable part of parliamentary communication, serving as a unique communicative code used by the MPs. The results stipulate further modelling of the parliamentary debates to build their interactive and cognitive models for better insight into the British political life and the British national character. The received knowledge is of particular importance for teaching country studies, history of the UK, political science, and speech communication theory.
\end{abstract}

Keywords: nonverbal communication, political discourse, parliamentary debates, proxemics, oculesics, tacesics, national character, traditionality.

Introduction

Being active subjects in creating language processes and phenomena, humans create various discourse practices to promote socialization and participate in the processes of categorization and systematization of the surrounding reality. Languages, social and communicative practices are interconnected, and it is highly observed in the political reality that penetrates and concerns all aspects of human activity and structures power relations in any society via the involvement of a wide range of communicants from various societal strata into the political communication.
Analysis of different aspects of political communication deepens understanding of the political picture of the world, national character, peculiarities of interaction, stereotypical communicative patterns inherent in any society. Political interaction patterns presuppose the usage of a wide range of verbal and nonverbal means. Nonverbal communication presupposes the exchange of meaningful information via body language to support verbal interaction and intensify its expressiveness and emotiveness. Such communication allows adding details to the messages, and it can encompass more detailed and more valuable information simultaneously with verbal messag- 
es than a particular separately produced verbal message. Nonverbals show the psychological and emotional state of communicants, their attitudes and hierarchical relations; they become markers of group identity and envisage the mode of behaviour accepted in a particular communicative situation. Nonverbal means in political communication highlight information on the roles, status and behavioural peculiarities of the political agents, and they serve as attentiontriggers for the general public.

The importance of interconnection between verbal and nonverbal communication means has always been in the focus of scholastic researches as humans use gestures and other nonverbal signs to communicate alongside, or even instead of speaking (McNeill, 2012). Scholars consider the gesture-first hypothesis, claiming that humans were able to communicate symbolically using nonverbal signs, and due to them, were able to develop the ability to use language signs (G. Hewes, E. Condillac, T. Bergin \& M. Fisch, M. Arbib, M. Corballis, A. Kendon, M. Tomasello, W. Stokoe etc.). Some works analyze the key properties of nonverbal communication, such as intentionality and referentiality, that are prerequisites for human language emergence and development (M. Cartmill, Call, J. Prieur \& J. Vauclair, S. Pika \& J. Mitani). Modern researches of communication processes focus on the nonverbal sign system as an indispensable part of human interaction that should be studied inseparably from the verbal means.

Nonverbal means that encompass gestures, eye contact, facial expressions, appearance, the distance between the communicants and other behavioural parameters become crucial in every sphere of human communication processes, underpinning interaction effectiveness. According to J. Clark and A. Paivio (1991), nonverbal are assumed to be processed efficiently and easily remembered and for this reason, they can dominate over verbal information. In the political sphere, nonverbal signs stipulate every political action or event, participating in conveying information, implementing ideas, creating specific images and influencing the electorate. The role of nonverbal communication in the political sphere is analysed in the works by E. Bucy, M. Korolko, A. Hanna, J. Yang, P. Steward, W. Gardner, W. Hart, M. Bloch, S. Rosenberg etc. The politicians' appearance and face expression are considered in the works by D. Ahler, M. Atkinson, K. Mattes, M. Hermann, P. Steward, B. Wallet, J. Schubert etc. Alongside such researches, understanding the peculiarities of nonverbal means usage in the political sphere presupposes a wide range of studies to explain the modern tendencies in political communication patterns within the political discourses.

Modern political studies concentrate on political philosophy aiming at analyzing principles of political and social life, including set of values and patterns of political institutions cooperation with public agents, united on topical political and sociocultural issues, together with conceptual systems and argumentation theories within the political sphere. Researches of political discourses, according to W. Lajul, are theoretical attempts at describing and explaining political philosophies and ideologies. Consequently, philosophical, political ideas or theories are also explained through philosophical and political discourses (Lajul, 2020, p. 177). D. Braybrooke states that in a broad sense, political philosophy embraces works like those of J. Rawls, R. Nozick, and D. Gauthier that deploy social contract theory, principles of justice, and rights in grand programs for social policy and political organization. Modern philosophical, anthropological 
and political approaches to political communication analyze systems of social control in societies, ways of reaching consensus and equality or inequality principles in the societies, critical approach towards discourse practices produced by institutional agents (J. Vincent, A. Subramanian, T. Lewellen, M. Aronoff and J. Kubik).

Parliamentary discourse as an integral part of political communication has become the object of scholarly research primarily in the fields of political philosophy, political sciences and sociology (P. Silk and R. Walters, R. Morgan and Cl. Tame, M. Olson and P. Norton, G. Copeland and S. Patterson), but only very recently it has become an interdisciplinary concern and involvement of different branches of linguistics (T. Carbó, S. Slembrouck, C. Ilie, I. Van der Valk, R. Wodak, T. van Dijk, J. Wilson and K. Stapleton etc.). Different specific features, structures and functions of parliamentary debates in different countries are analyzed in the works by A. Adonis, R. Bentley, W. Copeland, C. Patterson, R. Hart, and C. Landtsheer. Cognitive basis, ideological background, strategies and tactics of parliamentary debates as a type of discourse are specified in the works by D. Coombs, D. Kovachev, A. Baranov, E. Kasakevich, A. Romanov etc. Many scholars consider the rituals, customs and traditions that are highly observed during the parliamentary procedures and become the basis of verbal and nonverbal interaction patterns (W. Hauser and W. Singer, M. Banerjee, M. Weiner, R. Roy and P. Wallace etc.). In spite of the fact that parliamentary debates are in the focus of attention, the parliamentary debate in the UK as a speech genre that represents the unity of interrelated verbal and nonverbal communication means characterized by a number of the differentiating structural, semantic, pragmatic and cultural features have never been the subject matter of linguistic investigations. This fact determines the necessity of the research to envisage the whole spectrum of peculiarities inherent in the UK parliamentary debates that presuppose the nonverbal components of such debates. To fully understand verbal communication in the UK parliament as the main decision-maker of the nation, the multifaceted analysis of nonverbal components of MPs interaction should be considered. The purpose of this research is to study nonverbal means of parliamentary interaction in the UK that stipulate the effectiveness of the MPs interaction and fail-safe functioning of the UK parliament. The subject of the article encompasses proxemic, oculesic and tacesic parameters of MPs nonverbal interaction in the UK parliament.

High focus on different aspects of political communication, the appearance of new branches of political discourse analysis and its realization practices leads to the need for working out a new branch of political linguistics that considers parliamentary institutions. Taking into consideration the results of modelling the political discourse of the UK parliamentary debates', I formulate parliamentary discoursology as a new branch for analyzing the peculiarities and parameters of the parliamentary interactions within the scope of political discourse studies. Parliamentary discoursology unites the classical and modern approaches for analyzing political language within the political discourse, its peculiarities and functional potential. This branch focuses particularly on parliaments as highly conventional, structured and normalized political institutions with a number of interaction models and standardized verbal and nonverbal communication patterns.

This study is based on a wide variety of research principles and methods that help to analyze the UK parliamentary debates. They include cognitive mapping, genre modelling, contextual 
interpretation analysis, linguistic, stylistic analysis and componential analysis. The cognitive mapping specifies the genre, interactions of the participants in the debates and the conceptual structures within the discursive field of the UK parliamentary debates. Genre modelling defines the basic patterns, standards and norms, clarifies parameters of the UK parliamentary debates' modelling. Contextual interpretation analysis, together with linguistic, stylistic analysis and componential analysis, help to draw semantic meanings and stylistic means of lexical units in communicants' interactions. It is essential to focus on the contextual environment of the procedures of the debate. R. L. Heath and J. Bryant (1992) stress that the context of each communication event shapes it. In this sense, communication is embedded in a context, and interactive messages can only be fully understood by taking cognizance of the situation in which they occur (p. 57). Thus, it is necessary to study interpersonal communication within the parameters of what O. Hargie (1997) referred to as the personsituation context (p. 58).

To determine the genre peculiarities of the parliamentary debates, the analysis of the UK published Hansard reports, and the collection of recordings of the parliamentary procedures are used to deepen the conception of nonverbal aspects of communicants' interactions. To verify the correction, authenticity and objectiveness of the data received, the analyzed material includes parliamentary reports of the leaders of both Conservative and Labour parties in the post-Thatcher period.

Thus, a comprehensive analysis of the proceedings of the debate in the UK parliament presupposes an understanding of correlations of conceptual structures, language signs, nonverbal signs, contextual situation parameters, long-term established behavioural patterns and social structures. Understanding the nonverbal communication patterns in parliamentary debates contributes to a better understanding of the procedural peculiarities in the UK parliamentary life uncovering the peculiarities of the British national character.

\section{Research}

Political discourse reflects relations between the political agents and societies, being formed by means of power institutions and society integration, on the basis of the long-term established political culture and national political picture of the world that show national peculiarities of conceptualization and categorization of the reality. Parliamentary debates serve as a prototypical genre of political discourse due to their central place in the structure of this discourse, and their primary function is fighting for conquering, preserving and strengthening power. Such debates serve to intensify provision for the dominant position of political agents (communicants) in the political life of a nation.

Parliamentary debates are a complex communicative event in the form of a gradual deployment and with strict time and themes under discussion limits. They are characterized by a set of specific development patterns that involve theme and time regulators. This political discourse genre means the involvement of several communicants who are active participants in political interactions. They have strictly determined status-oriented hierarchical roles and functions. Communicants get involved in the discourse field of the debates, being united on the basis of common interests and solving existing sociopolitical issues within the country and abroad. Main purpose of the UK parliamentary debates is a constant participants' opinion interchange to 
solve existing issues in domestic and international politics. The more specific purpose of the communicants during the debates is an attempt to reach domination in the communicative interaction, gaining a leading position to demonstrate one's own problem-solving skills in the political, economic or social spheres for attracting electorate and increasing political power.

The parliamentary life in the UK is strictly stipulated by the norms encompassed in Erskine May that got the naming "the Bible of parliamentary procedure". This naming highlights the importance of this treatise in organizing the parliamentary life, structure, rights, norms, obligations and duties. For the UK parliament, where every meeting starts with prayers, the association of this treatise with the Bible demonstrates its status and importance in day-to-day parliamentary procedures. The participants in the parliamentary debates strictly follow norms and rules without violations, attempts to change, challenge or discuss them. The naming of the document is formed via metonymy as its author, Thomas Erskine May, created norms and rules of the British parliament. Later these norms turned to be called Erskine May. The peculiarities of the UK parliamentary debates are based on the Erskine May regulating the whole structure of the parliamentary life.

The political discourse of the UK parliamentary debates is researched within the scope of discourse analysis that aims at a complex study of genre and interactive features of this discourse genre. According to K. L. Hacker (1996), political, linguistic discourse analysis is a form of political communication research that focuses on how power and language are interrelated. It encompasses the correlation of power, cognition, communication and behaviour within the political discourse. The relations between state and society in the UK are based on democratic principles that determine certain communicative behaviour in political communication with the dominant open communication patterns. Such communication is predominantly directed towards bilateral interaction of competing parts, and active ideas exchange during the debates and mutual respect among participants in the parliamentary debates. The authoritative style of political communication means total control over thoughts expression, ideas interchange, and negative attitudes towards different opposing opinions. Turndown on initiative contradictory ideas in authoritative style leads to avoidance of prolonged discussions on existing issues. Compared to the authoritative type, the democratic style suggests rejection of oppressions and limitations of communicants' rights and freedoms during the parliamentary debates; it aims to create a balance of competing ideas and set equal participation, involvement, and opportunities for all Members of Parliament (MPs).

As a result, political discourse of the UK parliamentary debates is produced, developed and modified via rule of consensus through optimal balance and equality of MPs rights. This feature of the parliamentary debates in the UK influences the involvement of language structures within the discursive field of politics. The balance of political forces, their status in the debates is shown in the nonverbal communicative features and is reflected in the language forms of the terminological units.

The research of the UK parliamentary debates suggests a focus on genre peculiarities of the debates as the type of political discourse. Considering their structure, parliamentary debates are a specific dialogical unity that encompasses relative ties among the participants of political communication, peculiarities of their com- 
municative interaction aimed at the construction of political reality. Communicants in the parliamentary debates relate to each other through a set of long-established rules, norms and patterns of interparty relations that are based on hierarchical conventions. The primary mediator in such relations is verbal and nonverbal signs that reflect a strict, well-organized and structured system of the UK parliamentary debates.

Nonverbal parameters of the communicative process stipulate the peculiarities of the UK parliamentary debates' modelling. Nonverbal means of communication give the addressees some information, highlight the specific features of the cultural code of any nation, and traditions and norms of interaction; they show emotional state and speakers' attitude towards each other.

Nonverbal communication includes a set of nonverbal communicative means, signs, symbols and codes that play an essential role in understanding communicants' interaction. As has already been said, verbal communication, taken without context consideration, does not contain enough structural and semantic features characterizing their communicative status, and nonverbals help to promote better information understanding and decoding by showing communicative intentions. Nonverbal means add more meaning, expressiveness, and argumentation to the words communicants say. These means represent the ways of communicants' behavioural peculiarities in interactions, stipulating the additional meaning of speech acts, communicative moves, strategies and tactics of communication. Regarding their role in regulating the parameters of communication, such means of expression support a balanced level of communicants' interaction and indicate their communicative status.

Communication means conveying information through signals, as described by F. Man- del. We use body language without being aware of it, perceive and interpret other people's body language. Nonverbal phenomena are most important in the structuring and occurrence of interpersonal communication and the movement regulation of the interaction. Nonverbal signs help regulate the system, cueing hierarchy and priority among communicators, signalling the flow of interaction (Mandal, 2014).

Regulating the parameters of communication, nonverbals become one of the key elements of psychological interaction and hierarchical relations of the communicants during parliamentary debates. Such parameters have a strong influence on the procedural processes in the UK parliament.

A wide range of scholars claims that nonverbal behaviour is highly influenced by culture differences (e.g., Hall, E. T. \& Hall, M. R., 1990; Ekman \& Friesen, 1975; Matsumoto, 2006). Nonverbal means display traditionality, cultural code and norms of behaviour patterns of a certain language community, ethnos or group of people and help reconstruct their identity. The analysis of the parliamentary debates in the UK proves that nonverbal communication has a strong cultural and historical basis regarding following traditions and customs deeply embodied in the peculiarities of MPs interactions. They are motivated by the institutionalized norms and rules inherent in the political discourse type and are grounded on the old parliamentary laws and norms of debates procedures, reflecting the cultural code of participants in the parliamentary debates.

Model of the UK parliamentary debates is formed by nonverbal means including proxemics that encompasses the use of space embodied in distances and placements; tacesics expressed through touch behaviour; time regulators; physical appearance and behaviour of the communi- 
cants in the debates that form the base of all processes and functioning of all parliamentary procedures.

Proxemics as spatial orientation and status identification means of nonverbal communication is regarded as the basis of the UK parliamentary debates, showing the hierarchical roles of the MPs, their status in the procedures of the debate. Deepening knowledge of space usage helps to understand the UK parliamentary procedures better and to attract more public interest to the parliamentary life.

As stated earlier, nonverbal communication is highly influenced by cultural parameters. E. T. Hall, the cultural anthropologist, stresses that culture plays the definitive role in determining how individuals use personal space, e.g. that people from contact cultures choose closer distances, maintain more direct eye contact, touch each other more frequently, and speak more loudly than those from non-contact cultures (Hall, E. T. \& Hall, M. R., 1990). A. Brown and K. Starkey (1994) consider culture as a pattern of meanings inherited from the past which provides a means for interpreting the present. Culture in this sense refers to the traditional way of behaving in any particular context (Hargie, 1997, p. 58).

The UK parliamentary debates' genre model shows their normativity, processing patterns, hierarchical status and roles of their participants envisaging the ethnocultural features of the British. The model of the UK parliamentary debates embodies a unique system of communicants' status-motivated physical space usage, reflecting traditional features of the British national character and peculiar traits of the British political culture, associated primarily with traditionality shown in constant following and respecting the traditions and customs.

The participants in parliamentary debates assume specific political roles stipulated by their assignment in one of the two houses in a bicameral parliament. Space-motivated component is realized via communicants placements according to their position into the authority, opposition and non-factional MPs.Communicants allocation in the House of Commons and the House of Lords is unchangeable.

The Speaker's chair in the House of Commons is traditionally elevated, demonstrating his / her dominating status as a person who shapes all parliamentary procedures, controls debates issues and legislation, sets regulations, norms, and rules. The Chair is placed between the Government and the Opposition benches to imply that the head of the Housegoverns all the processes during the parliamentary debates remaining politically impartial and preserving equality in rights and obligations of all MPs. Such a Speaker placement provides for complete effectiveness of the regulatory mechanisms in the debates, especially during hot and sharp discussions in the House of Commons. Unlike the Speaker's elevated position in the House of Commons, the chair of the Speaker in the House of Lords is on the ground level that shows the equality of his / her status towards all the MPs. This norm is stipulated by the tradition of debates regulations that limit the Lord Speaker's interference with the House discussions as the MPs themselves are given the right to control and resolve all procedures.

Political life in the UK, especially its parliamentary system, is characterized by a strict following of the traditions, norms and customs. The peculiarities of the MPs allocation in the House of Lords and the House of Commons are in great relevance to the government and opposition. All political parties are precisely allocated in certain parts of the Chambers. The key figures 
- Her Majesty's Government and the Official Loyal Opposition Shadow Cabinet - are placed in the centre of the House of Commons, on the front benches, facing each other from the opposite sides; as a result, they are used to be called frontbenchers. Despite the leading parties, placed closer to the Speaker, parties' representatives who do not form the government or opposition, belong to other opposition parliamentary teams and do not strongly affect the country's legislative process get the remote places far from the Speaker of the House at the far end of the House (House of Commons Procedure and Practice, 2009), and they are called backbenchers.

The lexemes frontbenchers and backbenchers imply two components of meaning: in direct meaning, they suggest the placement of the MPs in the Chambers; in figurative meaning, they represent their status and role in the political life of the UK.For instance, in the debates on the election of a new Speaker, the communicant emphasizes the Speaker's role as the defender of the MPs rights and guarantee of their equality. The future Speaker has a commitment to keep a balance between the Government and the Opposition without referring to one party as the leading and humiliating the rights of others, as well as supporting one side of the parliament:

I know that you will be dedicated, that you are $100 \%$ committed to this House and that you will be fair to Front and Back Benchers (HC Deb 18 May 2010: Column 4).

Such namings are formed via the choice of motivator correlating with various terms in the propositional structure. In the case of MPs namings, they are represented by the activation of the locative term. Locative is considered as a space component in the propositional structures. The Prime Minister, together with the Leader of the Opposition, never changes places, unlike the other MPs who can change their location. Government officials from the sides of Her Majesty's Government and Her Majesty's Opposition are placed in the centre directly facing each other. The adversarial layout is influenced by tradition as it has been peculiar to the first permanent House of Commons in St. Stephan's Chapel (Commons Chamber, n.d.).

The placement of sits for the MPs realizes the idea of the competitive atmosphere for better questions and critical remarks' exchanging and peculiar political, theatrical performance staging to reach the communicative effect. The involvement of theatrics in the political sphere lays the basis for gaining and maintaining power in society. Political performance is conducted in a certain surrounding and with the usage of various communicative means according to strict rules and scenarios and is staged by actors/agents of the political life who pursue certain goals (Combs, 1981; Woods, 2006). K. Burke considers politics as a study of drama composed of many acts. The scholar points out that we view political action as a drama on a stage (Burke, 1967). This specific staged performance is, in fact, a competition where two leading sides are constantly opposing each other by means of demonstrating their strong sides and revealing weak sides of the opponents. They use various strategies and tactics involving face-saving and face-threatening acts. Such parliamentarians are called frontbenchers; this naming reflects their direct placing either in the House of Lords or the House of Commons. But it is also connected with the metaphorical association, based on their function, as these members of the British Parliament perform the leading function in the parliamentary procedures.

The first row on the right side from the Speaker is also named Treasury Bench. This 
naming is based on a metonymy according to the function of some MPs sitting on that bench LordoftheTreasury, who is in charge of economic policy in the country and perform an important role of political agents in the UK parliamentary life:

It is fair to say that over the last couple of days, exceptionally important matters have naturally dominated, but I hope that those on the Treasury Bench will have noted what has been said (HC Deb 17 Nov 2015: Column 552).

One more group of MPs that is also functionally important for the British parliament is called crossbenchers:

Independent Crossbenchers L. Hennessy of Nympsfield and L. Bilimoria spoke in this debate (HC Deb 9 October 2012: Column 1085).

Their status in the parliament determines the location of the crossbenchers: having no political parties' affiliation, they are situated between and perpendicularly towards the Government and Opposition. This naming shows that they are "on the crossroads" between the power and the opposition, belonging to no political party, and independently participating in political proceedings without sharing any common ideas. This group of MPs that encompasses life and hereditary peers becomes a differentiating feature of the House of Lords and is not inherent in the House of Commons.

As a result, the party affiliation and the political role in the UK parliamentary life are highlighted in the strict allocation of the MPs. Location stipulates communicants' participation in the procedures of the debate and provides wellorganized functioning of the Houses. These traditionally-inclined peculiarities are reflected in the language forms and the terms used to denote the MPs in the UK parliament perform some pragmatic functions: 1) to name the MPs; 2) to shape the parliamentary system into a wellordered structure; 3) to support hierarchical functioning of the debates; 4) to reflect on the status and role of MPs in the political life of the UK. In the modern democratic British society, where the public has full access to law-making processes via open sessions of the Parliament, the basic terminology system provides for a better public understanding of the procedures of the parliamentary debate and intensifies information dissemination. It stimulates social engagement and public interest in the political life of the country.

Thus, space parameters influence the system of language namings stipulated by some fundamental notions formed as the result of event perception and spatial cognition. Language is considered the means of passing cultural and political values within or between generations of people, provides a group or individual with a means of identification with a specific culture, values, or political entity (Denton \& Kuypers, 2008, p. 35). As referred to by G. Lakoff and M. Johnson, such lexical units as orientational metaphors are different from other metaphors because instead of structuring one concept in terms of another, they organize a whole system of concepts with respect to another. They function in correlation with the action of our body in the world (Lakoff \& Johnson, 2003). Language sings that structure political reality in the UK parliamentary life become major symbols accumulating certain traditions, patterns and roles that are long-established and well-checked through centuries of the well-oiled mechanism of parliamentary procedures. They help to determine spatial orientations in the UK political life.

The Speaker is in charge of communicants' placement during the debates. Distanced from the Speaker places are close to the Bar of the House, marked by a white line on the floor 
across the width of the House to identify the established boundaries for the visitors, i.e. the electorate and reporters, who are given the right to be present during the parliamentary meetings. Visitors are never allowed to voluntarily pass such boundaries; otherwise, it causes breaks of the parliamentary discipline.In the House of Lords, the Bar of the House is marked by a railing (UK Parliament, n.d.).

Communicants' distancing is stipulated by the two-sword lengths apart measure between red lines (3,96 metres). Red lines are drawn in front of governmental and oppositional benches to avoid trespassing that can cause physical contact during hot discussions in the debates. This peculiar feature of the debates is verbally expressed through the phraseological unit toe the line ("accept the authority, policies, or principles of a particular group, especially unwillingly" (Oxford Dictionaries, n.d.). This phraseological unit incorporates two meanings, denoting the process of limiting the members of the House movements during the debates and functioning the rule of strict party-line following.

Communicants in the parliamentary debates have the right to change their party affiliation willingly. In terms of political idioms, this right is denoted by the phraseological unit crossing the floor. Its motivation is two-faceted: this unit is based on the locative of communicants' placement, as they sit opposite each other and are subdivided into the government and opposition. Change of party affiliation means the placement change due to crossing the floor of the Parliament to join the party on the other side. At the same time, this lexical unit implies party affiliation change as MPs get the other status, new rights, obligations and functions, start to perform new political, and social, role in the United Kingdom.
Space also determines the naming of the House of Commons, Dispatch box, that is based on metonymy and features its function: the major participants in debates address from the wooden chair. Due to this, speaking from the dispatch box denotes the location of speakers in the House of Commons. In spite of the fact that the naming dispatch box is formed via metonymy, as this lexeme means "a container for official state or military dispatches" (Oxford Dictionaries, n.d.), the only official document that the dispatch boxes contain is the Bible ("and other items used when Members take the oath" (UK Parliament, n.d.).

Highly related to the proxemics is one more type of nonverbal communication termed oculesics and is related to eye contact, eye behaviour and vision-related aspects of communicative means. Eye contact, as a nonverbal means of communication, is usually used to set emotional contact between the communicants and to analyze the reactions to certain information provided. Considering the role of eye contact in the UK parliamentary debates, oculesics serves as a tool of attention-trigger and a determiner of MPs location.

Communicants' placement in the House of Commons during the parliamentary debates stipulates the opponents' eye contact as they are sitting face-to-face. According to A. Pease and B. Pease (2004), eye contact with opponents helps to reach understanding quicker (p. 175). This factor becomes an essential tool for reaching a compromise or getting support from all communicants in the parliamentary debates. It promotes an unobstructed implementation of amendments to the bills, stipulates changes in the course of actions or popularizes certain images of the MPs.

The House of Commons has a specific feature of attracting the Speaker's attention for par- 
ticipating in the parliamentary debates. In particular, to get the opportunity for debating, MPs need to turn Speaker's attention to them to be called to the Bar. To reach it, communicants usually raise from their sits to be seen by the Speaker. This performance is termed catching the Speaker's eye, as only such "catching" gives communicants a chance to ask questions or provide comments in the debates. For example, the communicant stresses the importance of catching the Speaker's eye to discuss some issues during the debates:

If the hon. Gentleman catches your eye, $\mathrm{Mr}$ Deputy Speaker, I am sure that we shall hear that Brighton, too, would benefit from a more flexible licensing regime (HC Deb 18 June 1999: Column 458).

Visual perception plays an important role in setting space parameters of the MPs and conducting the debates. As a result, the colours of the House of Commons and the House of Lords stipulate long-term established traditional namings that bear some strata-based symbolic meaning. Specifically, following the tradition of certain colour serves as a mediator in determining the locative of the Houses. Its usage in MPs benches, in official documents or reports, is obligatory. Green colour characterizes the House of Commons, and the red colour is traditional for the House of Lords.

The choice of green colour is deeply symbolic for the English ethnos, as a number of important factors stipulates it. Firstly, this colour is associated with nature, its fertility and gifts, and the peasants, people of non-noble origin. Secondly, green colour sets a connection with the historical past of the nation and religion, as during the Middle Ages, the English kings used to choose this colour in building churches and chapels (House of Commons Green, 2010). The red col- our in the House of Lords symbolizes the royal power, and it is widely used in the official royal ceremonies (UK Parliament, n.d.).

Since the MPs in the House of Commons are placed on the green benches, one of the widespread namings of the communicants is Green Benchers. This naming is formed via metonymy associated with a characteristic feature of agents' location on the specific places coloured green:

Her Majesty's Green Benchers - once such a proud fighting force, now cruelly depleted (the Daily Telegraph, 17 October 2013).

The colour of the location of the parliamentary debate is reflected in the details that show MPs placement. In particular, in the process of law approval, it is sent from the House of Commons into the House of Lords for further discussions. The document is wrapped with a ribbon that is coloured, either green or red. The colour of the ribbon helps to differentiate between the Houses, as the green colour symbolizes the House of Commons, and the red colour is distinctive for the House of Lords.

Tacesics becomes one more powerful means of MPs interaction during the parliamentary procedures in the UK House of Commons. Tacesic peculiarities as communicants' expressive-emphatic movements and actions in dynamic communicative interaction show complete firm respect towards traditions and norms of parliamentary practices meetings.

MPs placement determines and supports competitive spirit, strengthened by the team spirit as communicants with the same party affiliation are sitting together and have an opportunity to support each other during the debates in the UK parliament. The tradition demands their placement on special long benches touching each other's shoulders to feel support and unity.

After prolongation of the term in office or 
after the announcement about parliament's dissolution in case of parliamentary elections, all MPs shake hands with the Speaker before leaving the Chamber. In other situations, it is completely forbidden to shake hands with the higher-ranked MPs.

Speaker's appointment also supposes a certain performance that involves physical contact. The newly-elected Speaker is actually grabbed and pulled to rush him/her to take the Speaker's chair and preside over the procedures of the debate.

This tradition roots in the historical times when the Speaker of the House of Commons had to tell the monarch about the parliamentary events, and the monarch's disagreement with the political decisions could have led to the Speaker' execution. As a result, newly-elected Speakers rejected to take their position, and they were forced to preside in the House of Commons physically.

As the British reluctantly abandon their traditions, the ritualized act of the Speaker's appointment is still preserved, though its negative connotation is lost, and the process itself looks like a theatrical performance. The result of this theatrics is a considerable evaluation of an MP to the highest position in the House of Commons.

Despite quite an expressive behaviour of the British politicians during the parliamentary debates, exuberant ovations are non-typical. This norm in the House of Commons is stressed by the Speaker in the situation with discipline break when the MP has decided to support other communicant's words by means of clapping:

May I say at the start of the Parliament that the convention that we do not clap in this Chamber is very, very long established and widely respected, and it would be appreciated if Members showed some respect for that convention? (HC
Deb 27 May 2015: Column 55).

The Speaker immediately reacts to such support expression calling to keep order in the House of Commons. The Speaker highlighted the traditionality and conventions in MPs behaviour during the debates. He uses general question with arising intonation to add expressiveness to his words and simultaneously show impossibility to deviate from the existing long-term established norm and suggested following the tradetions. Here several markers of strengthening the importance are used: iteration of lexeme very that intensifies the meaning of the word combination long established and denotes its deep-rooted usage, expressive lexeme widely (used in the meaning "extensively and by many people") (Oxford Dictionaries, n.d.) to underline the importance to respect the norm by a certain group of people, and a repeated use of lexemes respect and respected. The Speaker also reminds about traditionality in debates procedures, and he attracts attention to the fact of norm-breaking in the Chamber due to an immediate detail of MPs location this Chamber of the House of Commons.

According to the Select Committee on the Modernisation of the House of Commons, spontaneous reaction of support realized in long-standing ovations does not interfere with the speech but can cause biased evaluation. Long-standing ovations show greater support due to the length of applause. A speech of communicants is estimated without its content, but considering the duration of clapping. In particular, norms and rules regulating MPs behavioural patterns during the debates in the UK parliament give detailed explanations on such a ban:

While we agree that spontaneous clapping at the end of a speech could in no way be interpreted as disturbance of the speaker, there is a danger that such a practice might be open to 
abuse and could lead in certain circumstances to the orchestration of what would amount to standing ovations with the success or failure of a speech being judged not by its content but by the relative length of the ovation at the end (Conduct in the Chamber, n.d.).

An expressive noun orchestration in the comments on clapping in the British parliament, taken from the musical sphere, strengthens negative attitude to applauses in the Chambers. The lexeme orchestration, used in the meaning "organization of something to achieve a particular result" (Cambridge Dictionary, n.d.), designates staging character and subjectivity of such an action that contradicts the position of the parliamentary debates objectivity.

Thus, this behavioural norm of applauses non-usage focuses primarily on objectivity in speeches perception and equal opportunities provided for all governmental and oppositional communicants. Applauses, in their turn, usually demonstrate complete support that leads to subjective opinions, break of the order and demonstration of opponents disrespect. Such actions in the Chambers undermine equality of all communicants' rights and impede the main principle of the parliamentary life - to hear everyone (hear him or her).

There are only several known recorded examples of clapping in the parliament, with the Speaker not intruding into the process. It happens in case of extra important events in the UK parliament, such as key bills approvals, prominent politicians' position appointment or resignation. For example, prime-minister T. Blair got longstanding ovations on his resignation day and left the House of Commons. The other example of the tradition break is ovations got by Sir R. Rodgers on stepping down from the position House of Commons Clerkafter 35 years of ser- ving to organize parliamentary procedure. House of Commons Clerk is the main counsellor on procedural issues in the parliamentary debates and is in charge of state funding expenditures. This position is traditional, as proved by the appearance of the clerk, who typically wears silk robes, a white collar and a wig (UK Parliament, n.d.). The important status and a long term in office provoked respect to the official. However, MPs reaction to such a rules break was ambiguous. The Conservative Party representative G. R. Mogg considered applauses in the House of Commons innovative, and this fact is usually against well-established norms and is not positively accepted by the conservative British society.

\section{Conclusion}

Proxemic parameters as a unique system of status motivated relations of the communicants in the UK parliamentary debates are based on traditionality and a long-term established cultural code. Proxemics peculiarities of the parliamentary debates are highly reflected in the language political terms used to name the communicants in the debates. These namings rely on the location of the MPs in the parliamentary Houses. Thus, orientation towards the centre of the Chambers determines the roles and statuses of the participants of the debate, as the main communicants are placed in the middle on the front benches that demonstrates their leading participation in the debates.

Oculesics is reflected primarily in the eye contact peculiarities of the MPs. Visual contact becomes the basis of influence on the political opponents and the tool of establishing a connection with the Speaker of the House of Commons and communicating with the prominent partici- 
pants in the debates. Triggering Speaker's attention is key for participating in the discussions during the parliamentary debates. Colour becomes highly symbolic and is motivated by traditions and social class; it plays a crucial role in determining spatial parameters of the debates communicants and the location of the parliamentary procedures.

Tacesics plays an important part via MPs tactic support due to their close placement during the procedures of the debate. Tacesics implies status-oriented hierarchical relations between the MPs and the Speaker of the House; it also shows traditionality in parliamentary communicative processes during ritualized Speaker's appointment procedure.

Thus, the nonverbal interaction in the UK parliamentary debates serves as a special communicative code shared by the MPs. This code is stipulated by the traditions, customs and norms developed within the centuries; they encompass the peculiarities of the British character and form the British political picture of the world, influencing the organizational structures and patterns of the parliament as the powerful decisionmaking political institution.

\section{References}

Brown, A., \& Starkey, K. (1994). The Effect of Organizational Culture on Communication and Information. Journal of Management Studies, 31, 807-828.

Burke, K. (1967). A Grammar of Motives. Berkeley, CA: University of California Press.

Cambridge Dictionary. (n.d.). Retrieved 18 November, 2020 from: https://dictionary.cambridge.org.
Clark, M., \& Paivio, A. (1991). Dual Coding Theory and Education. Educational Psychology Review, 3, 149-210.

Combs, J. (1981). Process Approach. Handbook of Political Communication. London: Sage Publications.

Commons Chamber. (n.d.). Retrieved 15 November, 2020 from: https://www.parliament.uk/about/living-heritage/building/palace/architecture/palace-s-interiors/commons-chamber/.

Conduct in the Chamber. (n.d.). Retrieved 15 November, 2020 from: https://publications.parliament.uk/pa/cm199798/cmse lect/cmmodern/600iv/md0404.htm.

Denton, R. Jr., \& Kuypers, J. A. (2008). Politics and Communication in America. Campaigns, Media and Governing in the 21 Century. Long Grove, Illinois: Waveland Press.

Ekman, P., \&Friesen W. V. (1975). Universals and Cultural Differencesin Facial Expressionsof Emotion. In Cole J. (Ed.), Nebraska Symposium on Motivation. Vol. XIX.(pp. 207-282). Lincoln: University of Nebraska Press.

Hacker, K. L. (1996). Political Linguistic Discourse Analysis. In M. E. Stuckey (Ed.), The Theory and Practice of Political Communication Research. (pp. 28-55). New York: State University of NewYork Press.

Hall, E. T., \& Hall, M. R. (1990). Understanding Cultural differences: German, French, and Americans. Yarmouth, ME: Intercultural Press.

Hargie, O. D. W. (1997). The Handbook of Communication Skills. London and New York: Routledge. 
Heath, R. L., \& Bryant, J. (1992). Human Communication Theory and Research: Concepts, Contexts and Challenges. Lawrence Erlbaum, Hillsdale, NJ: Lawrence Erlbaum Associates.

House of Commons Green. (2010). Retrieved 17 November, 2020 from: http://www.parliament.uk/documents/commons-information-office/g10.pdf.

House of Commons Procedure and Practice. (2009). ( $2^{\text {nd }}$ ed.). Retrieved 15 November, 2020 from: http://www.parl.gc.ca/procedure-book-livre/document.aspx?$\underline{\text { sbdid }=1 b 08 \mathrm{a} 55 \mathrm{c}-743 \mathrm{c}-47 \mathrm{db}-92 \mathrm{e} 0898 \mathrm{~d}-}$ $41340504 \&$ sbpidx $=4$.

Lajul, W. (2020).A Critical Analysis of Political Philosophy in African Political Discourses. Art Human Open Access Journal, 4(5), 176-185.

Lakoff, G., \& Johnson, M. (2003). Metaphors We Live By. London: University of Chicago Press.
Mandal, F. B. (2014). Nonverbal Communication in Humans. Journal of Human Behaviour in the Social Environment, 24(4), 417-421.

Matsumoto, D. (2006). Cultural Influenceson Facial Expression of Emotion. Southern Communication Journal, 56, 128137.

McNeill, D. (2012). How Language Began: Gesture and Speech in Human Evolution. University of Chicago.

Oxford Dictionaries. (n.d.). Retrieved 18 November, 2020 from: http://oxforddictionaries.com/.

Pease, A., \& Pease, B. (2004).The Definitive Book of Body Language.Pease International.

UK Parliament. (n.d.) Retrieved 15 November, 2020 from: https://www.parliament.uk.

Woods, N. (2006). Describing Discourse: A Practical Guide to Discourse Analysis. Trans-Atlantic Publications. 